\title{
Efforts to Improve Competency of Teacher MGMP Chemistry, Padang City Through Training For Development of Teaching Materials Based on Guided Discovery Learning
}

\author{
Yerimadesi $^{\mathbf{1}^{*}, \text { Bayharti }^{1}, \text { Guspatni }^{\mathbf{1}}, \text { Ellizar }^{\mathbf{1}} \text {, dan Andromeda }}{ }^{\mathbf{1}}$ \\ ${ }^{1}$ Jurusan Kimia, Universitas Negeri Padang, Jl. Prof. Dr. Hamka, Air Tawar, Padang 25131, Indonesia \\ * Correspondence: yeri@fmipa.unp.ac.id; Tel.: +062-813-6347-4938
}

Diterima 8 Desember 2018, Disetujui 25 November 2019 Dipublikasikan 30 November 2019

\begin{abstract}
This article is compiled based on the results of community service activities through the community partnership program of Padang State University in 2018 year. This activity aims to improve the competence of chemistry teachers in Padang City chemistry group through training based on guided discovery learning materials. The way to implement these activities can be done through training and workshops to 53 Padang chemistry group teachers. The instruments used were questionnaires for teacher and student responses. The product trial was carried out on 27 students of class X at Padang 1 Public High School in the 2018/2019 academic year. Data analysis was performed using percentage techniques and moment Cappa Cohen's. From the results of the questionnaire analysis of the chemistry teacher's response to the implementation and presentation of the material by the resource persons in succession, the average percentage percentage was $88 \%$ and $91 \%$ with the second category of aspects that being assessed very high. From the questionnaire analysis of teacher and student responses to learning using chemical modules based on guided discovery learning (GDL), the mean value of the kappa moment was 0.85 for the teacher's questionnaire responses with very high categories and 0.70 for the responses questionnaire of students with high categories. It was concluded that training in the preparation of teaching materials based on guided discovery learning could improve the competence of chemistry group teachers.
\end{abstract}

Keywords - chemistry group, guided discovery learning, learning material, teacher competence, training

\begin{abstract}
Abstrak - Artikel ini disusun berdasarkan hasil kegiatan pengabdian kepada masyarakat melalui program kemitraan masyarakat Universitas Negeri Padang tahun 2018. Kegiatan ini bertujuan untuk meningkatkan kompetensi guru-guru kimia MGMP kimia Kota Padang melalui pelatihan penyusunan bahan ajar berbasis guided discovery learning. Metode pelaksanaan kegiatan dengan memberikan pelatihan dan workshop kepada 53 orang guru kimia MGMP Kota Padang. Instrumen yang digunakan berupa angket respon guru dan siswa. Uji coba produk dilakukan kepada 27 orang siswa kelas X di SMA Negeri 1 Padang tahun ajaran 2018/2019. Analisis data dilakukan dengan teknik persentase dan momen Cappa Cohen's. Dari hasil analisis angket respon guru kimia terhadap penyelenggaraan dan penyajian materi oleh nara sumber secara berturut-turut diperoleh rata-rata persentase penilaian sebesar $88 \%$ dan $91 \%$ dengan kategori kedua aspek yang dinilai sangat tinggi. Dari analisis angket respon guru dan siswa terhadap pembelajaran menggunakan modul kimia berbasis guided discovery learning (GDL) diperoleh nilai rata-rata momen kappa 0,85 dari angket respon guru dengan kategori sangat tinggi dan 0,70 dari angket respon siswa dengan kategori tinggi. Disimpulkan bahwa kegiatan pelatihan penyusunan bahan ajar berbasis guided discovery learning dapat meningkatkan kompetensi guru-guru kimia MGMP kimia.
\end{abstract}

Keywords — bahan ajar, guided discovery learning, kompetensi guru, pelatihan

This is an open access article distributed under the Creative Commons 4.0 Attribution License, which permits unrestricted use, distribution, and reproduction in any medium, provided the original work is properly cited. (C2017 by author and Universitas Negeri Padang. 


\section{Pendahuluan}

Kurikulum 2013 mensyaratkan pembelajar-an menggunakan pendekatan saintifik dimana siswa didorong untuk aktif menemukan konsep dan mengembangkan pengetahuan, sikap dan keterampilan. Salah satu model yang disarankan untuk mengimplementasikan pendekatan saintifik adalah model belajar penemuan atau discovery learning (Kemendikbud, 2014).

Discovery learning merupakan suatu model pembelajaran yang dapat meningkatkan hasil belajar dan keterampilan berpikir siswa (Balim, 2009 dan Udo, 2010). Guided discovery (penemuan terbimbing) merupakan salah satu tipe model discovery leaning yang paling memotivasi siswa, karena penguatan yang diberikan oleh guru dalam bentuk dorongan dan dukungan (bahkan jika siswa tidak menemukan jawaban yang benar) guru tetap memotivasi siswa untuk terus bekerja sampai akhirnya siswa menjadi lebih termotivasi. Dalam guided discovery, guru merencanakan suatu rangkaian pernyataan atau pertanyaan yang membimbing siswa, langkah demi langkah secara logis, membuat serangkaian penemuan yang mengarah ke tujuan yang telah ditentukan. Dengan kata lain guru memulai stimulus dan siswa bereaksi dengan terlibat dalam penyelidikan secara aktif sehingga menemukan respon yang tepat (Smitha, 2012). Oleh karena itu model guided discovery leaning ini paling sesuai dengan karakteristik siswa SMA yang masih membutuhkan bimbingan (Udo, at al., 2010 dan Akinbobolaa, at al., 2010).

Guided discovery dapat meningkatkan keterampilan berpikir kritis siswa, seperti pada pembelajaran kimia SMA (Yerimadesi, 2018dan pembelajaran matematika (Aksu, G. \& Koruklu, N. (2015). Penerapan model guided discovery learning pada pembelajaran kimia juga dapat meningkatkan daya ingat siswa dibandingkan menggunakan metode konvensional (Lasisi, 2016). Selanjutnya Sumiadi (2016), melaporkan bahwa pengembangan perangkat pembelajaran berbasis pendekatan saintifik model guided discovery dikategorikan baik dan sangat baik sehingga layak untuk digunakan pada proses pembelajaran biologi di SMA Negeri 1 Bayan karena dapat mengefektifkan penguasaan konsep siswa.

Dalam Kurikulum 2013 juga diterangkan pentingnya bahan ajar untuk dapat mempermudah siswa memahami materi pelajaran.Penggunaan bahan ajar bahkan menjadi sesuatu yang tak terpisahkan dari setiap model pembelajaran yang dipilih. Bahan ajar adalah seperangkat materi yang disusun secara sistematis sehingga tercipta suasana yang memungkinkan siswa belajar (Depdiknas, 2008). Bahan ajar yang dapat digunakan guru bisa berupa (1) bahan ajar cetak seperti buku, modul, LKS, (2) bahan ajar berbasis komputer seperti $C D$ interaktif, dan (3) bahan ajar berbasis web.

Guru merupakan komponen pendidikan yang sangat berperan penting dalam kegiatan pembelajaran. Guru merupakan tenaga profesional yang melakukan tugas pokok dan fungsi meningkatkan pengetahuan, keterampilan, dan sikap peserta didik sebagai aset Indonesia di masa depan. Seperangkat tugas yang harus dilaksanakan oleh seorang guru berhubung dengan profesinya sebagai seorang pengajar. Tugas guru ini berkaitan dengan kompetensi profesionalnya dalam pembelajaran.

Scales (2011) dalam bukunya "Continuing Professional Development in the Lifelong Learning Sector", mengemukakan bahwa ada dua bagian penting yang berkaitan dengan professional guru. Pertama, guru harus secara berkesinambungan meningkatkan kemampuannya terkait kemampuan dalam mengajarkan bidang studi yang diampu (kompetensi professional). Kedua, guru harus secara berkesinambungan meningkatkan kemampuan mengelola pembelajaran di kelas (kompetensi pedagogik). Untuk meningkatkan kedua kompetensi tersebut, guru dapat mengikuti berbagai pelatihan yang difasilitasi oleh sekolah atau instansi pendidikan lainnya. Selain itu, guru dapat mengikuti pertemuan reguler antar guru dalam wadah Musyawarah Guru Mata Pelajaran (MGMP).

. Untuk meningkatkan kompetensi guru, maka guru membutuhkan pelatihan dan bimbingan untuk mengembangkan kompetensi profesionalnya. Hal ini terbukti dalam permohonan yang diajukan oleh MGMP Kimia Kota Padang kepada Lembaga Penelitian dan 
Pengabdian Masyarakat Universitas Negeri Padang (LP2M UNP) untuk memberikan pelatihan penyusunan bahan ajar bagi guru-guru kimia SMA Se-Kota Padang. Berdasarkan surat permohonan yang diajukan ini, terlihat bahwa MGMP Kimia Kota Padang sangat berharap untuk diadakannya kegiatan ini. Hal ini dibuktikan dari isi surat permohonan yang diberikan, surat permohonan juga di tandatangani oleh ketua MGMP Kimia SMA Kota Padang dengan tembusan kepada: (1) Kepala Dinas Provinsi Sumatera Barat, (2) Ketua MKKS/MKKSS SMA Kota Padang; (3) Pengawas Kimia SMA Kota Padang; dan (4) Koordinator Kimia Kota Padang.

Berdasarkan hal diatas, maka rumusan masalah dalam kegiatan ini adalah: "Apakah pelatihan penyusunan bahan ajar berbasis guided discovery learning dapat menambah pengetahuan, wawasan dan keterampilan guruguru MGMP Kimia Kota Padang untuk melaksanakan pendekatan saintifik sesuai dengan tuntutan Kurikulum 2013? Kegiatan pengabdian kepada masyarakat ini bertujuan untuk meningkatkan kopetensi guru-guru MGMP kimia kota Padang, terutama kompetensi profesional dan pedagogi melalui pelatihan penyusunan bahan ajar berbasis guided discovery learning. Lebih jauh diharapkan kegiatan ini dapat menambah pengetahuan, wawasan dan keterampilan guru-guru MGMP Kimia Kota Padang untuk melaksanakan pendekatan saintifik sesuai dengan tuntutan Kurikulum 2013.

\section{Solusi/Teknologi}

Berdasarkan analisis situasi, permasalahan guru dan kajian teoritis yang telah dilakukan, maka diputuskan bahwa pelatihan dapat membantu guru untuk menyusun dan mengembangkan bahan ajar kimia SMA. Ketersediaan bahan ajar akan membantu guru memfasilitasi siswa untuk melaksanakan pendekatan saintifik dalam pembelajaran kimia. Adapun materi dan kegiatan yang dilakukan adalah (1) model pembelajaran guided discovery learning, (2) Penyusunan bahan ajar berbasis guided discovery learning untuk pembelajaran kimia SMA/MA (3) Panduan pembuatan bahan ajar kimia dengan microsoft word, (4) Workshop pembuatan bahan ajar kimia dengan microsoft word, (5) Workshop penyusunan bahan ajar dalam bentuk modul kimia berbasis guided discovery learning untuk SMA/MA, dan (5) Uji coba bahan ajar dalam bentuk modul kimia berbasis guided discovery learning kepada siswa SMA. Di akhir kegiatan, guru mengumpulkan bahan ajar berbasis guided discovery learning untuk membantu guru memfasilitasi pendekatan saintifik pada proses belajar siswa.

Pelatihan ini diberikan kepada guru-guru kimia anggota MGMP Kimia Kota Padang. Setelah pelatihan ini, diharapkan guru mendapatkan pengetahuan yang lebih baik tentang pendekatan saintifik, model pembelajaran guided discovery learning dan bahan ajar berbasis guided discovery learning sehingga tuntutan Kurikulum 2013 dapat terpenuhi. Dengan mengikuti pelatihan ini, diharapkan guru dapat menyusun bahan ajar sendiri atau berkelompok melalui kegiatan MGMP, sehingga guru akan terbantu dalam menerapkan pendekatan saintifik dan model pembelajaran sesuai tuntutan kurikulum yang berlaku.

\section{Hasil dan Diskusi}

Berdasarkan hasil analisis evaluasi penyelenggaraan (Tabel 1) diperoleh nilai persentase penyelenggaraan PKM sebesar 88\% dengan kategori sangat tinggi. Data ini menunjukkan bahwa penyelenggaraan PKM sudah sesuia dengan semestinya, mulai dari kesiapan administrasi/sekretariat, humas dan dokumentasi, tempat ; materi, konsumsi/akomondasi, acara pembukaan, pelaksanaan penyajian, pelaksanaan diskusi, kegiatan sosisalisasi, dan pelaksanaan penutupan.

Tabel 1. Hasil Analisis Evaluasi Penyelengaraan Kegiatan PKM

\begin{tabular}{clcc}
\hline No & $\begin{array}{c}\text { Aspek yang } \\
\text { Dievaluasi }\end{array}$ & Persentase & Kesimpulan \\
\hline 1 & $\begin{array}{l}\text { Kesiapan } \\
\text { Administrasi } \\
\text { /Sekretariat }\end{array}$ & 90 & Sangat Tinggi \\
2 & $\begin{array}{l}\text { Kesiapan Humas } \\
\text { dan dokumentasi }\end{array}$ & 89 & Sangat Tinggi \\
3 & Kesiapan Tempat & 90 & Sangat Tinggi
\end{tabular}




\begin{tabular}{clcc}
\hline No & $\begin{array}{c}\text { Aspek yang } \\
\text { Dievaluasi }\end{array}$ & Persentase & Kesimpulan \\
\hline 4 & $\begin{array}{l}\text { Kesiapan Materi } \\
\text { Kesiapan } \\
\text { konsumsi }\end{array}$ & 92 & Sangat Tinggi \\
6 & $\begin{array}{l}\text { Kesiapan Acara } \\
\text { Pembukaan }\end{array}$ & 88 & Sangat Tinggi \\
7 & $\begin{array}{l}\text { Pelaksanaan } \\
\text { Penyajian } \\
\text { Pelaksanaan }\end{array}$ & 87 & Sangat Tinggi \\
8 & $\begin{array}{l}\text { Diskusi } \\
\text { Kegiatan }\end{array}$ & 87 & Sangat Tinggi \\
10 & $\begin{array}{l}\text { Sosisalisasi } \\
\text { Pelaksanaan } \\
\text { Penutupan }\end{array}$ & 86 & Sangat Tinggi \\
\hline & Nilai rata-rata & 88 & Sangat Tinggi \\
\hline
\end{tabular}

Berdasarkan hasil evaluasi penyajian materi oleh narasumber diperoleh sebesar $91 \%$ dengan kategori sangat tinggi. Data ini menunjukkan bahwa penyajian materi oleh narasumber berjalan dengan lancar, hal ini juga didukung oleh sudah disiapkannya sarana yang dibutuhkan oleh panitia di sekolah, seperti mic, warles, layar dan LCD. Dengan demikian materi yang ditargetkan sesuai dengan tujuan kegiatan dapat disampaikan semuanya oleh narasumber. Pesertapun dapat mengikuti dengan baik, karena sudah diberikan hard copy materi tersebut pada waktu registrasi. Selain itu narasumber juga memberikan soft copy beberapa buku teks yang bias dijadikan sebagai sumber rujukan oleh peserta dalam menyusun bahan ajar, baik buku-buku berbahasa Inggris maupun berbahasa Indonesia dalm dua buah flash disk yang bisa dipindahkan oleh peserta ke laptop masing-masing secara bergiliran.

Tabel 2. Hasil Analisis Evaluasi Penyajian

\begin{tabular}{|c|c|c|c|}
\hline No & $\begin{array}{c}\text { Aspek yang di } \\
\text { Evaluasi }\end{array}$ & Persentase & Kesimpulan- \\
\hline 1 & $\begin{array}{l}\text { Ketepatan waktu } \\
\text { penyajian }\end{array}$ & 95 & $\begin{array}{l}\text { Sangat } \\
\text { Tinggi }\end{array}$ \\
\hline 2 & $\begin{array}{l}\text { Kesiapan bahan } \\
\text { ajar }\end{array}$ & 93 & $\begin{array}{l}\text { Sangat } \\
\text { Tinggi }\end{array}$ \\
\hline 3 & $\begin{array}{l}\text { Penguasaan materi } \\
\text { pelatihan }\end{array}$ & 94 & $\begin{array}{l}\text { Sangat } \\
\text { Tinggi }\end{array}$ \\
\hline 4 & $\begin{array}{l}\text { Sistematika } \\
\text { penyajian materi }\end{array}$ & 91 & $\begin{array}{l}\text { Sangat } \\
\text { Tinggi }\end{array}$ \\
\hline 5 & $\begin{array}{l}\text { Cara/metode } \\
\text { penyampaian } \\
\text { materi }\end{array}$ & 92 & $\begin{array}{l}\text { Sangat } \\
\text { Tinggi }\end{array}$ \\
\hline 6 & $\begin{array}{l}\text { Kemampuan } \\
\text { mentransfer materi }\end{array}$ & 92 & $\begin{array}{l}\text { Sangat } \\
\text { Tinggi }\end{array}$ \\
\hline
\end{tabular}

\begin{tabular}{|c|c|c|c|}
\hline No & $\begin{array}{c}\text { Aspek yang di } \\
\text { Evaluasi }\end{array}$ & Persentase & Kesimpulan \\
\hline & pelatihan & & \\
\hline 7 & $\begin{array}{l}\text { Penguasaan kelas } \\
\text { dan komunikasi } \\
\text { dengan peserta }\end{array}$ & 92 & $\begin{array}{l}\text { Sangat } \\
\text { Tinggi }\end{array}$ \\
\hline 8 & $\begin{array}{l}\text { Kemampuan } \\
\text { memotivasi peserta } \\
\text { pelatihan }\end{array}$ & 92 & $\begin{array}{l}\text { Sangat } \\
\text { Tinggi }\end{array}$ \\
\hline 9 & $\begin{array}{l}\text { Kemampuan } \\
\text { menjawab } \\
\text { pertanyaan peserta } \\
\text { pelatihan }\end{array}$ & 92 & $\begin{array}{l}\text { Sangat } \\
\text { Tinggi }\end{array}$ \\
\hline 10 & $\begin{array}{l}\text { Perhatian terhadap } \\
\text { pendapat \& } \\
\text { pertanyaan peserta }\end{array}$ & 89 & $\begin{array}{l}\text { Sangat } \\
\text { Tinggi }\end{array}$ \\
\hline 11 & $\begin{array}{l}\text { Efektivitas } \\
\text { penggunaan waktu } \\
\text { pelatihan }\end{array}$ & 88 & $\begin{array}{l}\text { Sangat } \\
\text { Tinggi }\end{array}$ \\
\hline 12 & $\begin{array}{l}\text { Kemampuan } \\
\text { instruktur secara } \\
\text { keseluruhan }\end{array}$ & 92 & $\begin{array}{l}\text { Sangat } \\
\text { Tinggi }\end{array}$ \\
\hline 13 & $\begin{array}{l}\text { Tingkat penyerapan } \\
\text { materi pelatihan } \\
\text { oleh peserta secara } \\
\text { keseluruhan }\end{array}$ & 88 & $\begin{array}{l}\text { Sangat } \\
\text { Tinggi }\end{array}$ \\
\hline 14 & $\begin{array}{l}\text { Alokasi waktu yang } \\
\text { disediakan }\end{array}$ & 84 & $\begin{array}{l}\text { Sangat } \\
\text { Tinggi }\end{array}$ \\
\hline \multicolumn{2}{|c|}{ Nilai rata-rata } & 91 & $\begin{array}{l}\text { Sangat } \\
\text { Tinggi }\end{array}$ \\
\hline
\end{tabular}

Berdasarkan Tabel 3 terlihat guru memiliki respon yang sangat tinggi $(\mathrm{k}=0,85)$ terhadap kegiatan penyusunan bahan ajar dan pembelajaran menggunakan modul kimia berbasis guided discovery learning (GDL).

Tabel 3. Analisis Angket Respon Guru terhadap Penyusunan dan Pembelajaran Menggunakan Modul Kimia Berbasis Guided Discovery Learning (GDL)

\begin{tabular}{clcl} 
No & $\begin{array}{l}\text { Aspek yang } \\
\text { dievaluasi/Pernyataan }\end{array}$ & $\begin{array}{c}\text { Nilai } \\
\mathrm{k}\end{array}$ & Kesimpulan \\
\hline $\begin{array}{l}\text { Saya senang menyusun } \\
\text { bahan ajar dalam bentuk } \\
\text { modul kimia berbasis } \\
\text { guided discovery learning } \\
\text { Ketersedian beberapa } \\
\text { buku sumber kimia/ }\end{array}$ & 0,87 & Sangat Tinggi \\
$2 \begin{array}{l}\text { literatur membantu saya } \\
\text { dalam menyusun modul } \\
\text { kimia berbasis guided } \\
\text { discovery learning } \\
\text { Adanya panduan } \\
\text { penyusunan modul yang } \\
\text { diberikan instruktur } \\
\text { memudahkan saya dalam }\end{array}$ & 0,86 & Sangat Tinggi \\
& 0,85 & Sangat Tinggi \\
\end{tabular}




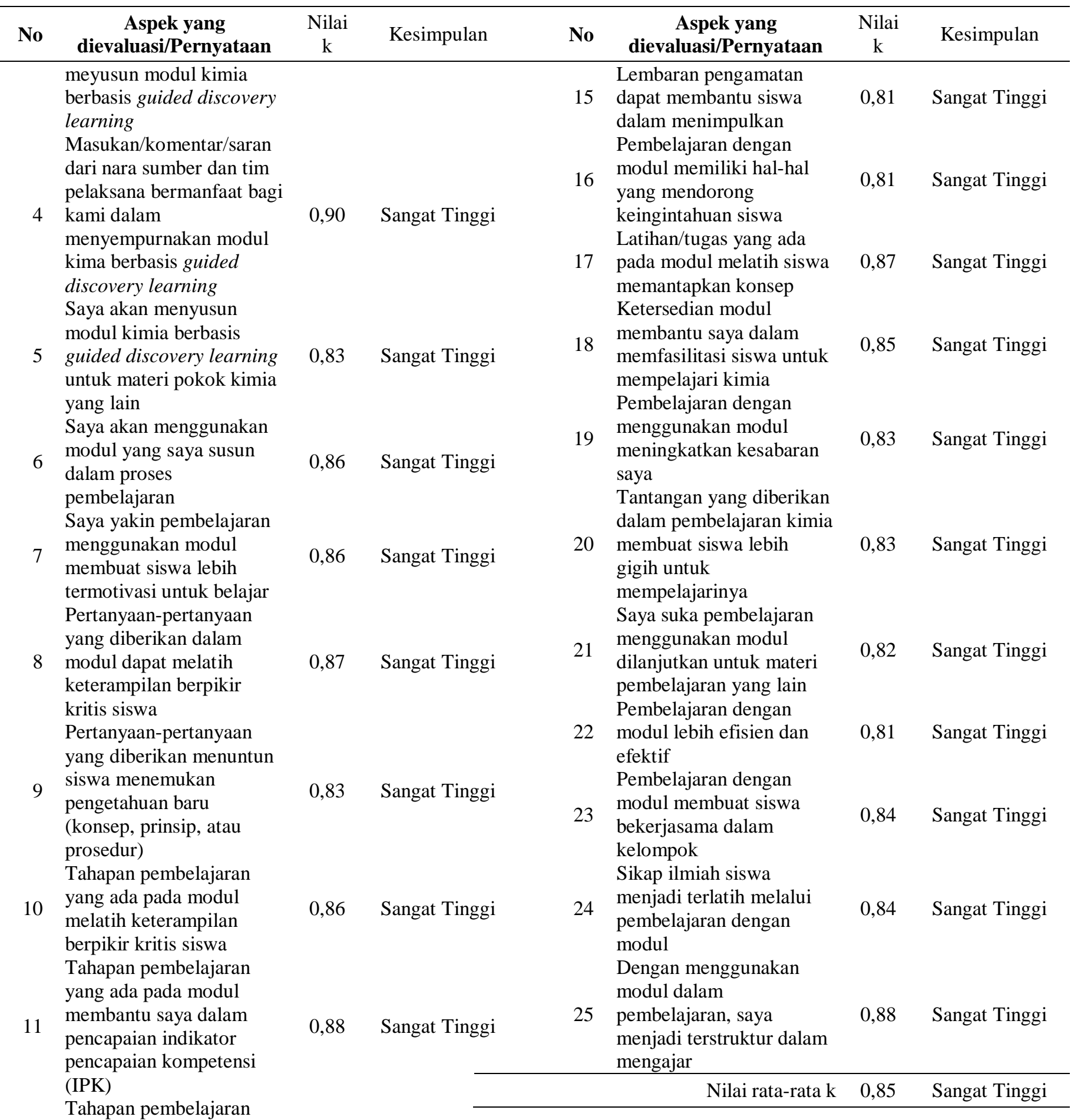
yang ada pada modul

12 membantu saya dalam menerapkan pendekatan

0,88 Sangat Tinggi saintifik

Siswa menjadi aktif

13 belajar dengan menggunakan modul dalam pembelajaran Pengumpulan data melalui

14 percobaan membantu siswa dalam menemukan konsep 


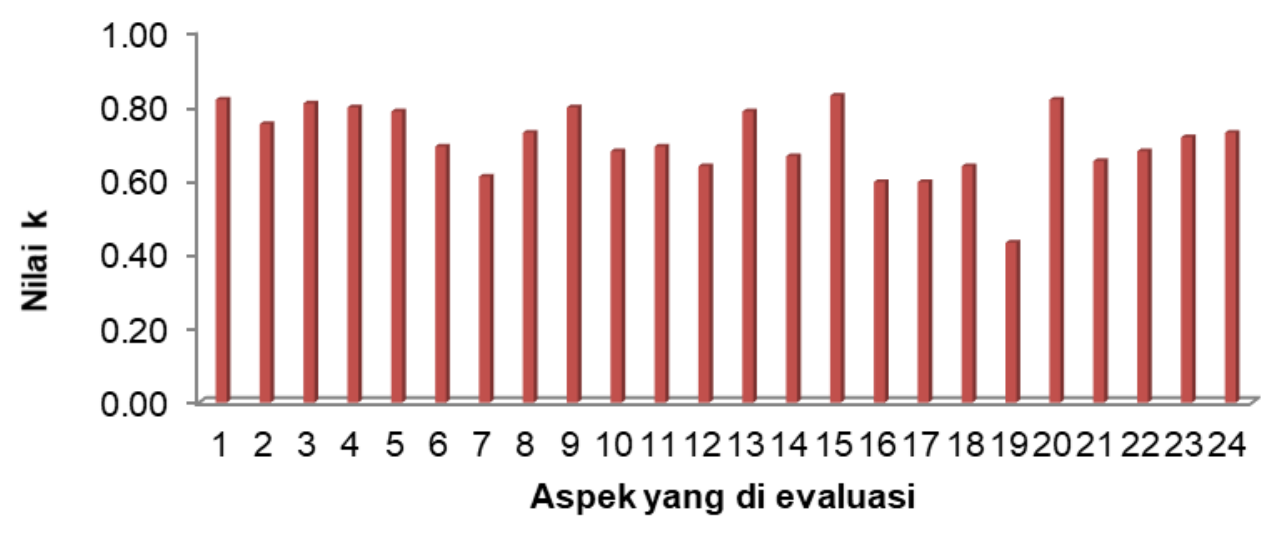

Gambar 1. Hasil Analisis Angket Respon Siswa terhadap Pembelajaran Menggunakan Modul Kimia Berbasis Guided Discovery Learning (GDL)

Aspek yang dievalusi terdiri dari 24 pernyataan, yaitu sebagai berikut ini.

$1=$ Saya senang belajar dengan menggunakan modul ini

$2=$ Modul yang diberikan guru membuat saya lebih termotivasi untuk belajar kimia

$3=$ Pertanyaan-pertanyaan yang diberikan dalam modul melatih saya untuk berpikir kritis

$4=$ Pertanyaan-pertanyaan yang diberikan menuntun saya menemukan pengetahuan baru

$4=$ (konsep, prinsip, atau prosedur)

$5=$ Tahapan pembelajaran yang ada pada modul melatih keterampilan berpikir saya

$6=$ Saya menjadi aktif belajar dengan menggunakan modul dalam pembelajaran kimia

$7=$ Percobaan yang ada pada modul mudah dikerjakan

$8=$ Pengumpulan data melalui percobaan membantu saya dalam menemukan konsep

$9=$ Lembaran pengamatan saya isi dengan jujur

$10=$ Saya melakukan percobaan dengan senang

$11=$ Pembelajaran ini memiliki hal-hal yang mendorong keingintahuan saya

$12=$ Saya semangat mengikuti pembelajaran dengan menggunakan modul ini

$13=$ Dalam kegiatan pembelajaran saya mengikuti dan berusaha memperoleh nilai tinggi

$14=$ Latihan/tugas yang ada pada modul menyenagkan saya

$15=$ Bimbingan yang diberikan guru membantu saya memahami materi pembelajaran

$=$ kimia

$16=$ Pembelajaran dengan menggunakan modul meningkatkan rasa disiplin saya

17 = Tantangan yang diberikan dalam pembelajaran ini membuat saya lebih giat belajar

$18=$ Saya suka pembelajaran menggunakan modul kimia dilanjutkan untuk materi

pembelajaran yang lain

$19=$ Pembelajaran dengan modul memakan waktu yang lama

$20=$ Pembelajaran dengan modul membuat saya bekerjasama dalam kelompok

$22=$ Pembelajaran dengan modul membuat saya lebih bertanggungjawab

$23=$ Pembelajaran dengan modul meningkatkan rasa percaya diri saya

$24=$ Sikap ilmiah saya menjadi terlatih melalui pembelajaran dengan modul 
Dari 24 aspek yang dievalusi oleh siswa diperoleh rata-rata nilai momen Cappa sebesar 0,70 dengan kategori tinggi. Data ini menunjukkan bahwa penggunaan modul dapat memotivasi belajar siswa. Hasil yang diperoleh sama dengan yang dilaporkan oleh Akinbobola dan Afolabib (2010), yaitu dari hasil penelitiannya diperoleh bahwa motivasi siswa dalam sains dan teknologi dapat dicapai dengan penerapan model GDL. Dengan perencanaan yang baik, GDL dapat mendorong dan memotivasi siswa untuk berlatih dan menerapkan pengetahuan ilmiah yang diperoleh dengan situasi baru dengan memanfaatkan keterampilan proses sains. Hal ini disebabkan karena pembelajaran penemuan mengacu pada pembelajaran yang langsung diperoleh siswa sendiri, bukan dari hasil penyajian materi pelajaran yang siap saji (readymade knoowledge) oleh guru. Artinya, siswa dimotivasi agar memerdayakan potensi nalarnya agar mampu menemukan saling hubungan semua elemen yang ada dalam setiap materi atau pengetahuan dalam kurikulum sekolah (Ansyar, 2015).

Hasil penelitian yang sama dilaporkan oleh Balım (2009), berdasarkan pertanyaan yang diberikan pada siswa sewaktu penelitian yaitu "apakah kamu menyukai pembelajaran dengan discovery learning?" didapatkan jawaban bahwa semua siswa sangat menyukai pembelajaran dengan model discovery learning. Menurut siswa pembelajaran dengan model discovery learning lebih menyenangakan dan menguntungkan, karena mengizikan siswa untuk menyusun aktivitas dan menggunakan material serta teknik yang berbeda. Siswa juga mengemukakan bahwa model discovery learning mendidik, menyenangkan dan bermanfaat dari pada metode tradisional.

Guided discovery merupakan model pembelajaran yang paling memotivasi siswa, karena penguatan yang diberikan oleh guru dalam bentuk dorongan dan dukungan, bahkan jika siswa tidak menemukan jawaban yang benar guru tetap memotivasi siswa untuk terus bekerja sampai akhirnya siswa menjadi lebih termotivasi (Smitha, 2012). Hal ini disebabkan karena ketika siswa menerima dukungan yang cukup dalam mengembangkan pengetahuan yang diperlukan, guided discovery learning dapat membantu siswa untuk menjadi lebih termotivasi, mengembangkan pengetahuan yang fleksibel, dan belajar bagaimana pengetahuan dikembangkan dalam domain tertentu (Janssen, at al., 2014). Hasil penelitian yang sama juga dilaporakan oleh Otiende, at al. (2013), bahwa guided discovery learning memiliki pengaruh yang sangat signifikan terhadap motivasi dan prestasi siswa dengan meningkatkan retensi pengetahuan dan kepercayaan diri siswa.

\section{Kesimpulan}

Berdasarkan kegiatan PKM yang dilakukan terhadap guru-guru MGMP kimia Kota Padang, dapat disimpulkan bahwa kegiatan pelatihan penyusunan bahan ajar berbasis guided discovery learning dapat meningkatkan kompetensi guruguru kimia baik dari segi pedagogik maupun profesionalisme. Kegiatan ini juga bermanfaat bagi guru dalam melaksanakan tugas pembelajaran dan dalam meintegrasikan penerapan model pembelajaran ke dalam bahan ajar.

\section{Saran}

Berdasarkan kegiatan yang telah dilakukan, disarankan beberapa hal berikut ini: (1) Perlu kegiatan lanjutan yang terkait peningkatan kualitas pendidikan dan pembelajaran di sekolah bagi guru-guru, terutama kegiatan yang dapat menunjang dan membantu guru untuk mengembangkan kariernya atau naik pangkat, seperti penyusunan perangkat pembelajaran oleh MGMP kimia yang bisa diterbitkan oleh penerbit dan digunakan bersama di semua sekolah di Kota Padang khusunya dan Sumatera Barat umumnya. (2) Perlu juga dilakukan kegiatan pelatihan dan workshop lainnya, seperti pelatihan pengelolaan laboratorium kimia, penyusunan soal-soal Hots, penyusunan bahan ajar berbasis kewirausahaan. 


\section{Ucapan Terima Kasih}

Penulis mengucapkan terimakasih kepada Lembaga Penelitian dan Pengabdian Masyarakat (LP2M) Universitas Negeri Padang, yang telah mendanai penelitian ini melalui Dana DIPA Universitas Negeri Padang Tahun Anggaran 2018 sesuai dengan Surat Keputusan Rektor UNP Nomor SP DIPA-042-01.2400929/2018 Tanggal 5 Desember 2017.

\section{Pustaka}

Akinbobola, A.O. dan Afolabib. F. 2010. Constructivist practices through guided discovery approach: The effect on students' cognitive achievement in Nigerian senior secondary school

Aksu, G. \& Koruklu, N. 2015. Determination the effects of vocational high school students' logical and critical thinking skills on mathematic success. Eurasian Journal of Educational Research, 59, hlm: 181-206

Balim, A.G. 2009. The Effects of Discovery Learning on Students' Success and Inquiry Learning Skills. Egitim ArastirmalariEurasian Journal of Educational Research. No. 35. Hlm: 1-20.

Brady, J.E. 2003. Chemistry Matter and Its Changes. Four Edition. Willey International Edition: New York.

Bicknell-Holmes, T. \& Hoffman, P. S. 2000. Elicit, engage, experience, explore: Discovery Learning in Library Instruction. Reference Services Review, 28(4).

Bruner, J. S. 1961. The Act of Discovery. Harvard Ed Rev, 31, 21-32.

Carin, A. A. 1997. Teaching Science Through Discovery. $8^{\text {th }}$. Ed. Upper Saddle River, New Jersey Columbus, Ohio: Pearson Prentice Hall, Inc.

Chang, R. 2003. General Chemistry, The Essential Conceots, Third Edition, Mc Graw Hill, New York.

Depdiknas. 2008. Panduan Pengembangan Bahan Ajar. Jakarta: Departemen Pendidikan Nasional.

Depdiknas. 2008. Pengembangan Bahan Ajar. Jakarta: Departemen Pendidikan Nasional, Direktorat Jenderal Manajemen Pendidikan
Dasar dan Menengah, Direktorat Pembinaan Sekolah Menengah Atas.

Joyce, B., Weil, M., \& Calchoun, E. 2009. Models of Teaching. $8^{\text {th }}$. Ed. Baston: Allyn and Bacon.

Kemendikbud. 2014. Peraturan Mentri Pendidikan Dan Kebudayaan Republik Indonesia Nomor 59 Tahun 2014 Tentang Kurikulum 2013 SMA/MA. Jakarta: Dirjen Menteri Pendidikan Dan Kebudayaan Republik Indonesia.

Lasisi, N., Alabi, T. O. and Salaudeen, M.B. (2016), "Comparison of the effects of guided discovery, problem solving and conventional teaching methods on retention of secondary school Chemistry students in Minna Metropolis, Niger State", American Journal of Innovative Research and Applied Sciences, Vol. 2 No. 3, pp: 98-104.

Nasution, S. 2011. Berbagai Pendekatan dalam Proses Belajar dan Mengajar. Jakarta: Remaja Rosdakarya.

Permendikbud Nomor 59 Tahun 2014 tentang Kurikulum 2013 Sekolah Menengah Atas/Madrasah Aliyah.

Purwanto, C.E. Sunyoto E.N., dan Wiyanto. 2012. Penerapan Model Pembelajaran Guided Discovery pada Materi Pemantulan Cahaya untuk Meningkatkan Berpikir Kritis. UPEJ (Unnes Physics Education Journal) Vol 1. Tahun 2012. http://journal.unnes.ac.id/sju/index.php/upej. Sanjaya, W., 2013, Perencanaan dan Desain Sistem Pembelajaran, Jakarta: Kencana Prenadamedia Group.

Smitha, VP. 2012. Inquiry Training Model and Guided Discovery Learning For Fostering Critical Thinking And Scientific Attitude. First Edition. Publisher Vilavath Publications, Kozhikode.

Sumiadi, Raden, dkk. 2016. Pengembangan Perangkat Pembelajaran berbasis Pendekatan Saintifik Model Guided Discovery dan Efektifitasnya terhadap Penguasaan Konsep Biologi Siswa SMA Negeri 1 Bayan. Jurnal Penelitian Pendidikan IPA, 51-59.

Wahyuni, T., Tukiran, Wahono W. 2014. Pengembangan Perangkat Pembelajaran 
Kimia Analisis dengan Menerapkan Model Pembelajaran Guided Discovery untuk Melatih Pemahaman Konsep dan Keterampilan Berpikir Kritis Siswa SMK. ejournal.unesa.ac.id/article.

Udo, M. E. 2010. Effect of Guided-Discovery, Student- Centred Demonstration and the Expository Instructional Strategies on Students' Performance in Chemistry. Jurnal Multi-Disiplin Internasional, Ethiopia; Vol. 4 (4), Serial No. 17, October, 2010. Pp: 389-398 